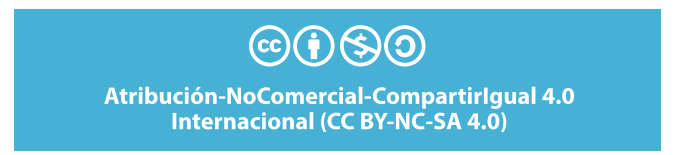

DOI: http://dx.doi.org/10.20983/reij.2021.2.5
Kelly Orellana Faz

César Enderica Guin

FECHA DE RECEPCIÓN: 29 de noviembre 2020

FECHA DE ACEPTACIÓN: 05 febrero 2021

\title{
LA IMPUTACIÓN OBJETIVA EN EL CÓDIGO ORGÁNICO INTEGRAL PENAL ECUATORIANO
}

\author{
Objective Imputation in the Ecuadorian Comprehensive Organic Criminal Code
}

\section{Resumen:}

En el presente artículo científico, enfocado en el análisis de la teoría de la imputación objetiva aplicada en el Código Orgánico Integral Penal, es un tema que ha sido discutido respecto al momento de la atribución de un resultado típico a la cuenta de un sujeto. El objetivo de la investigación es analizar las diversas teorías que nacen de la imputación objetiva a fin de demostrar la importancia de la dogmática penal, al existir desconocimiento en este campo, ya que esta teoría va más allá de la práctica o la literalidad de la normativa. El Código Orgánico Integral Penal ha acogido como antecedentes el estudio de las escuelas del derecho penal, teniendo en cuenta que es la escuela funcionalista la que se encuentra en vigencia. Se han analizado las propuestas dogmáticas de Gunter Jacobs y Claus Roxin, grandes profesores del derecho penal. La metodología de la investigación por su naturaleza es documental, descriptiva, deductiva -cuantitativa, ya que se pudo llegar a conclusiones específicas por medio de las encuestas realizadas a la población de abogados de la ciudad de Guayaquil, registrados en el Colegio de Abogados de las Guayas hasta el año 2019. Se pudo concluir que el Código Orgánico Integral Penal reúne todas las teorías derivadas de la escuela funcionalista. A criterio de juristas, en nuestro país no se vivió la transición del finalismo al funcionalismo, limitándose así una defensa completa y adecuada.

Palabras claves: derecho penal, teoría, conducta, escuelas, resultado

\begin{abstract}
:
In this scientific article, focused on the analysis of the theory of objective imputation applied in the Comprehensive Organic Criminal Code, it is a topic that has been discussed regarding the moment of attribution of a typical result to a subject's account. The objective of the research is to analyze the various theories that arise from the objective imputation in order to demonstrate the importance of criminal dogmatics, since there is ignorance in this field, since this theory goes beyond the practice or the literality of the regulations. The Comprehensive Organic Criminal Code has taken as a background the study of the schools of criminal law, taking into account that it is the functionalist school that is in force. The dogmatic proposals of Gunter Jacobs and Claus Roxin, great professors of criminal law, have been analyzed. The research methodology by its nature is documentary, descriptive, deductive-quantitative, since it was possible to reach specific conclu-
\end{abstract}


sions through the surveys carried out to the population of lawyers of the city of Guayaquil, registered in the Guayas Bar Association until the year 2019. It was possible to conclude that the Comprehensive Organic Penal Code brings together all the theories derived from the functionalist school. In the opinion of jurists, our country did not experience the transition from finalism to functionalism, thus limiting a complete and adequate defense.

Keyword: criminal law, theory, behavior, schools, result

\section{Introducción}

En el presente artículo científico se estudiará la imputación objetiva en el derecho penal ecuatoriano, al ser una teoría relevante en el campo jurídico-científico dentro de un proceso penal. Para mayor entendimiento del lector, se expondrá como antecedentes la escuela dogmática donde surge dicha teoría, esto es, la escuela moderna o también denominada funcionalista, donde se tratará sobre las dos formas de funcionalismo existentes desde la perspectiva de Roxin y Jacobs, consecuentemente previo al análisis profundo del tema principal.

Se expondrá lo referente a la conducta penalmente relevante por ser la rama que da origen a la imputación objetiva, la cual será analizada de forma general, pues en el ámbito penal es indispensable sostener el correcto manejo, ubicación y aplicación de esta teoría, a fin de evitar la vulneración de derechos que pueda acarrear la falta de conocimiento del ámbito científico. Se manifestará cómo el Código Orgánico Integral Penal, lo introduce en nuestra norma, acotando además que Ecuador tuvo un cambio brusco pero innovador de la escuela neo-causalista al funcionalismo, ya que el finalismo no se vivió en el derecho penal ecuatoriano.

Posterior a esto, se analizará de forma fraccionada las vertientes que surgen, las cuales son: la imputación objetiva de la conducta o comportamiento y la imputación 
objetiva del resultado. Cabe acotar que cada vertiente en mención posee divisiones, como son: el riesgo no permitido, el principio de confianza, la prohibición de regreso y el vínculo objetivo del comportamiento y resultado obtenido, vínculos derivados, respectivamente. Éstas a su vez poseen pequeñas ramas o subvertientes, que sirven para la aplicación de los múltiples escenarios delictivos que se puedan percibir, en concordancia con la fenomenología existente en Ecuador.

\section{Metodología de la investigación}

Tipo de investigación

- Documental. La investigación documental es una técnica que consiste en la selección y compilación de información a través de la lectura y crítica de documentos y materiales bibliográficos, bibliotecas, bibliotecas de periódicos, centros de documentación e información.

- Descriptiva. Este tipo de estudio busca describir de forma ordenada y lógica situaciones o acontecimientos; básicamente no está interesado en comprobar explicaciones ni en probar determinadas hipótesis, ni en hacer predicciones.

- Deductiva. En el presente artículo el método deductivo ha sido aplicado mediante el análisis de los estudios realizados por diversos autores, que dan sus puntos de vista sobre la teoría de la imputación objetiva. Nosacoge- mos a las ideas generales de la dogmática penal para definir nuestra postura específica y particular.

- Cuantitativa. El enfoque cuantitativo ha sido utilizado mediante las encuestas realizadas a los profesionales del derecho de Guayaquil registrados en el Colegio de Abogados hasta el año 2019.

\section{Técnica e instrumentos}

- Técnicas de investigación bibliográfica. En el presente artículo se ha utilizado la técnica bibliográfica, puesto que se ha recolectado información de todas las fuentes disponibles en textos tangibles así como virtuales, como lo son: libros jurídicos, ejemplares de revistas científicas penales, artículos científicos referentes al derecho penal, entre otros.

\section{Planteamiento del problema}

Dentro del desarrollo del estudio de la dogmática jurídica penal ecuatoriana, seguimos a la escuela funcionalista al momento de imputar un resultado. Entendemos que, por la ciencia penal, el delito contiene sus propios elementos, tiene una conducta penalmente relevante que es típica, antijurídica y culpable, y ésta a su vez tiene elementos que la excluyen. En el derecho penal ecuatoriano existen instituciones jurídicas acogidas en su norma, sin embargo, existe la carencia de la aplicación 
de la ciencia jurídica en un proceso, puede ser desde la perspectiva de la defensa técnica, dejando de lado la parte esencial del derecho penal.

\section{Imputación objetiva en el derecho penal ecuatoriano}

\section{Antecedentes}

Las bases de donde surge la imputación objetiva es en el causalismo, implementado por Liszt y Bering, donde se hace referencia a la relación existente entre el hecho y el resultado o consecuencia. Dicha teoría era considerada naturalística, pero no se basaba en el análisis de un acto como una acción natural. Los causalistas fraccionaban esta teoría entre un movimiento corporal que producía un cambio en el mundo exterior, además de los componentes del nexo causal físico y el resultado.

Con el paso del tiempo esta dogmática fue evolucionando y complementándose, fue así como en el periodo del neo-causalismo prevalecía una corriente neokantista . Se sustituye a aquella acción natural por el término de acción bajo un concepto más social, es decir, ya se hace referencia a una conducta humana, abarcando así la acción y la omisión.

Posterior a esto surge el finalismo, en el cual se resalta la acción finalista; fue implementada por Hans Welzel , quien indicaba que la acción no era social sino netamente jurídica, por lo cual existía la capacidad de prevención ante los efectos que pudiera traer consigo dicha actuación. También surgió la del tipo complejo, en la que básicamente se trataba de incluir el denominado dolo dentro del tipo finalista, y este a su vez dentro de la culpabilidad. Finalmente concluimos con la teoría funcionalista, que es la que predomina hasta la actualidad y de la cual haremos énfasis a posteriori por ser la que perfecciona la imputación objetiva.

El ámbito de aplicación de esta teoría fue inicialmente para los delitos dolosos de resultado. Actualmente en el ordenamiento jurídico penal ecuatoriano es aplicado a todos los tipos penales independientemente de su naturaleza, ya sean delitos de resultado o de mera actividad, sean por acción, por omisión, dolosos o imprudentes, incluso hasta en la tentativa.

En la práctica procesal se observa la aplicación de esta teoría en el principio de legalidad; enfocados en materia penal (art. 76.3 de la Constitución de la República del Ecuador) vemos que más bien lo exalta y garantiza con mayor efectividad su aplicación, concreta limitadamente el ámbito de lo prohibido por el tipo o lo que la norma quiere evitar para proteger los bienes jurídicos.

La teoría de la imputación objetiva permite que administradores de justicia apliquen de manera ordenada y estructurada una teoría jurídica penal, y puedan llevar una correcta y unificada aplicación de la norma de forma lógica, lo que lleva a radi- 
car más la seguridad jurídica, tomando en cuenta la exigencia de protección que tiene un estado constitucional de derechos y justicia como el nuestro.

- Teoría funcionalista. La teoría funcionalista nace en el año 1980 y es denominada en el mundo del derecho penal como la teoría moderna o post-finalista. Surge con posterioridad a la teoría finalista, en ella se implementan grandes cambios en lo referente a la dogmática penal, esto es, se eliminan por completo los rasgos causalistas antiguos. El funcionalismo rige en la actualidad en nuestro sistema ecuatoriano, recogido correctamente en el Código Orgánico Integral Penal.

Ya no se hace uso de la terminología de "acto" usada en el neo-causalismo, ni como "acción finalista”, pues el término correcto que se emplea con el inicio de esta escuela es "conducta penalmente relevante", la cual hace referencia al concepto social de una acción (personas jurídicas, naturales; acción u omisión). Su autor o creador es el alemán Claus Roxin (bajo principios de la filosofía), sin embargo, se incorporan los tintes ideales acotados por Günther Jakobs (derecho penal del enemigo), quien era más radical. De esta escuela surgen las vertientes del funcionalismo moderado y normativista, ambas aplicadas en propor- ciones idóneas dieron paso a la teoría de la imputación objetiva.

- Funcionalismo moderado. Esta vertiente del finalismo es implementada, como lo menciono en líneas anteriores, por Claus Roxin, también era conocida como la parte teológica de aquella escuela del derecho. Estaba vinculada con la política criminal; en ella se indica que la tipicidad se enlaza con el principio denominado nullum crimen, nulla poena sin lege. Aquí encontramos tintes del neokantismo incorporado por Roxin, quien manifestó que: "toda estructura del delito debe ir encaminado hacia un propósito, en el que no puede separarse de la política criminal, del Estado con la Constitución y el bloque de constitucionalidad que ella integra y en tal caso ningún principio debería ir en contra de ésta."

- Funcionalismo normativista. Esta vertiente del funcionalismo la implementó Günther Jakobs, también denominada como funcionalismo radical $\mathrm{o}$ extremista, ya que contraria al funcionalismo moderado, esta dogmática poseía tintes del derecho penal del enemigo, cuyo autor era el mismo Jakobs. En general se hacía referencia a que toda persona que pertenece a la sociedad, debía cumplir un rol determinado y que cuyo desempeño traería consigo satisfacer las exceptivas que versan sobre 
él, pues caso contrario, al no cumplirlas con mera obediencia, podría decirse que se incurre a la defraudación de dichas expectativas sociales que podrían ser reprimidas.

- Conducta penalmente relevante. La implementación de la conducta penalmente relevante, reemplazando a la acción finalista, en el caso de Ecuador, deroga al denominado "acto" neocausalista (ya que nuestro país no pasó por las influencias del finalismo). Ésta se encuentra tipificada en el art. 22, del vigente Código Orgánico Integral Penal, que de forma textual manifiesta: "Son penalmente relevantes las acciones u omisiones que ponen en peligro o producen resultados lesivos, descriptibles y demostrables." Es decir, que las modalidades de la conducta penalmente relevante son tanto por acción como por omisión, lo cual como se mencionó anteriormente implica el concepto social de una acción, esto se encuentra en el art. 23 del COIP.

- La imputación objetiva en Ecuador. La imputación objetiva posee una doble vertiente, la cual causa gran confusión a muchos de los profesionales del derecho en nuestro país, esto es la imputación objetiva de la conducta o el comportamiento y la imputación objetiva del resultado.

La teoría de la imputación objetiva se sintetiza del siguiente modo: "un resultado causado por el sujeto que actúa sólo debe ser imputado al causante como su obra y sólo ha cumplido el tipo objetivo" "cuando el comportamiento del autor haya creado un riesgo no permitido para el objeto de acción y cuando el riesgo se haya realizado en el resultado concreto» $\mathrm{y}$ «cuando el resultado se encuentre dentro del alcance del tipo».

La teoría de la imputación objetiva es una herramienta para interpretar adecuadamente si el suceso o acontecimiento puesto en marcha por una persona debe ser apreciado como un acontecer socialmente relevante o irrelevante, como socialmente extraño o adaptado. (Zambrano, 2000).

"Otra de las ideas preconizadas por Roxin es el concepto de la imputación objetiva, que originó una gran discusión en torno a los conceptos de causalidad e imputación en el Derecho Penal. La estructura planteada por Roxin complementa de cierta forma el tipo objetivo; otra idea que organiza este y que de cierta medida también será idea de Jakobs es el binomio culpabilidad-prevención." (Derecho Venezolano, s.f.)

De forma sencilla podría indicarse que la imputación objetiva, se define como aquel análisis que se debe realizar sobre una conducta, la misma que debe poner en un peligro real un bien jurídico protegido por el Estado, es decir, se hace referencia a la conexión entre un comportamiento o una conducta y un resultado o consecuencia, a la cual la entrelaza o une la causalidad. 
Ilustración 1. Ubicación de la imputación objetiva

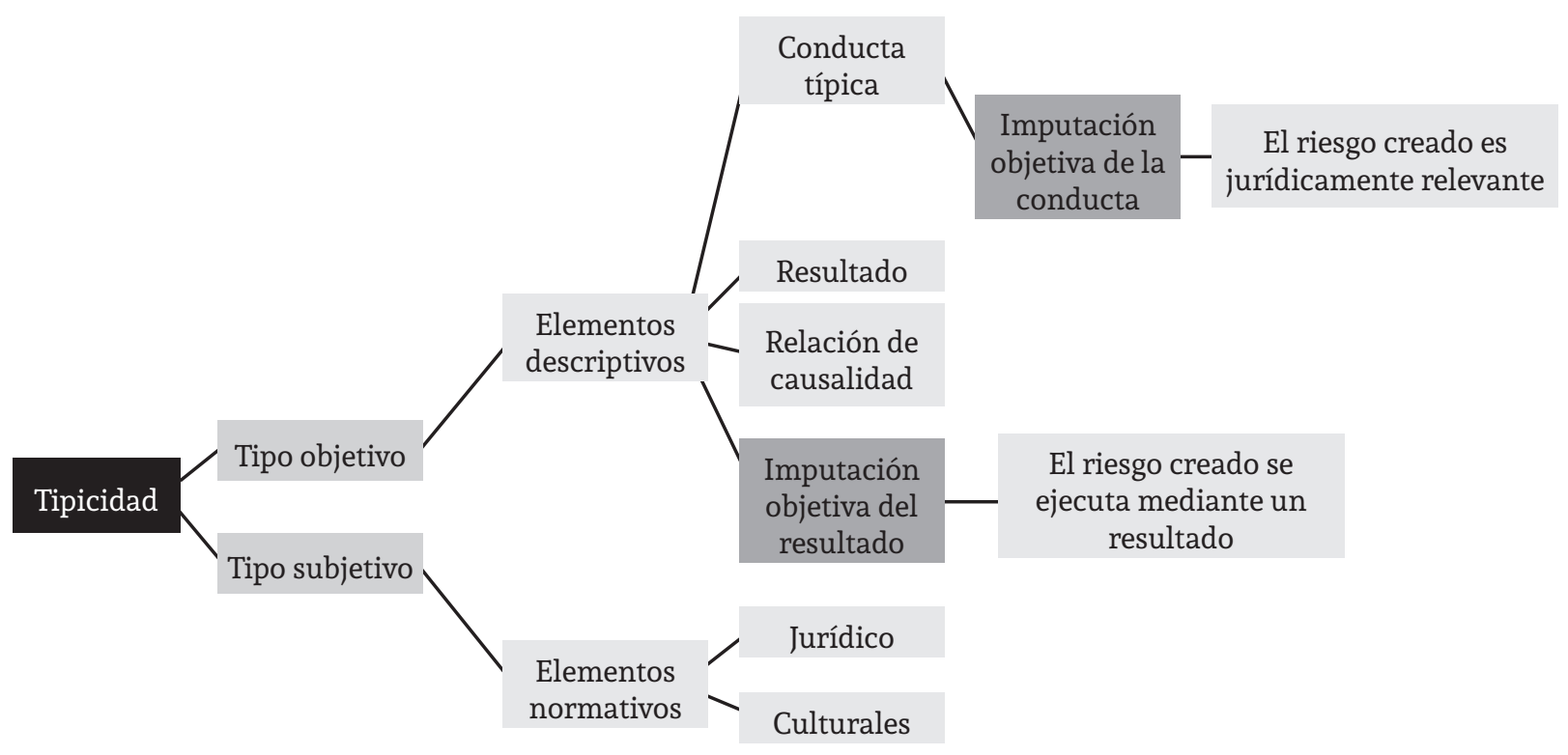

Elaborado por: Orellana, K. (2020); Enderica, C. (2020)

Esta conexión debe adecuarse a un tipo penal enmarcado en la normativa vigente, en este caso, el Código Orgánico Integral Penal, es decir, debe ser relevante, capaz de perjudicar el bien en mención. Siendo indispensable mostrar estos supuestos al momento de que la defensa técnica plantee la imputación objetiva, como un mecanismo de defensa a favor de su cliente.

Es indispensable tener en cuenta que el análisis minucioso de esta conducta bajo esta teoría, marcará el destino de un individuo en lo que respecta a un juicio de reproche, pues bien, no todo el daño que perjudique a un bien jurídico protegido se enmarcará siempre en el tipo objetivo, pues se efectúa en aquellos casos en donde se ha actuado, por ejemplo, bajo un estado de necesidad, enmarcando así esta conducta en el tipo subjetivo de la tipicidad, resaltando que hay teorías que pueden suprimir a la denominada imputación objetiva.

La teoría de la imputación objetiva se encuentra dentro del tipo, antes de la antijuricidad e incluso antes de la tipicidad subjetiva. Fue implementado por el tan reconocido Claus Roxin, relacionando así la acción con el tipo objetivo. Básicamente, lo que hace la imputación objetiva es determinar el escenario en donde deben aplicarse las diversas teorías existentes o las situaciones que éstas abarcan.

Un ejemplo de ésta sería que A, mientras conducía, tuvo una llamada y producto de esta distracción lesionó a $B$, quien es un peatón que cruzaba la calle en ese momento. Analizando este ejemplo, podríamos determinar que sin existencia de esta denominada imputación objetiva no se podría determinar a quién se le atribuye dicho 
Ilustración 2 . Imputación objetiva.

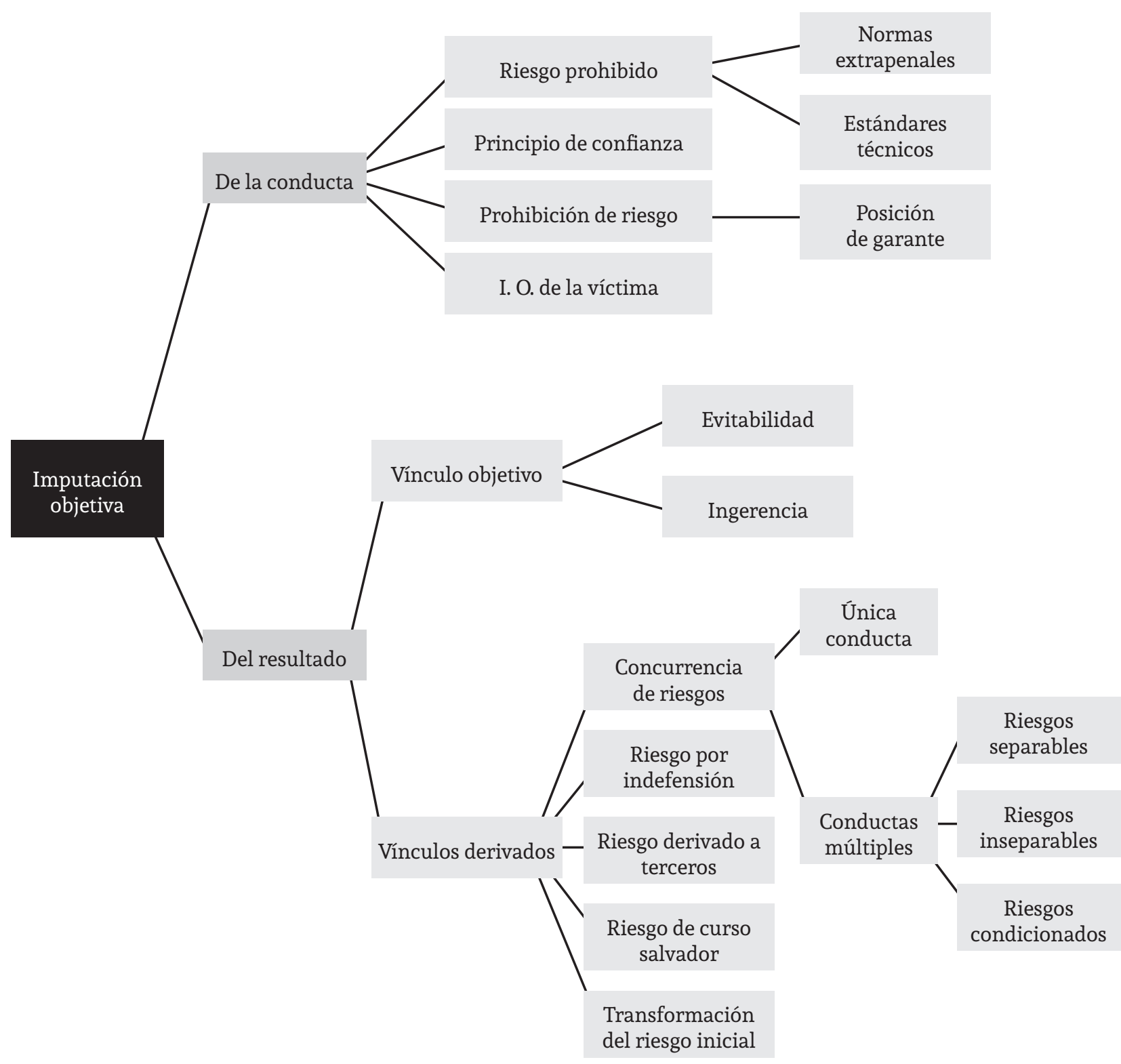

Fuente: Aula virtual de la Escuela de la Función Judicial, Abg. Costaín Vásquez, M. (2018).

Elaborado por: Orellana, K. y Enderica, C. (2020).

resultado, pues bien se podrían interpretar diversos escenarios, como por ejemplo: $B$ tuvo la culpa por cruzar la calle, o A tuvo la culpa por atender el teléfono; incluso se podría atribuir la responsabilidad a la persona que llama al conductor, o a la perso- na que envió a $\mathrm{B}$ a realizar determinado evento que lo sacó de su domicilio; es por eso que la imputación objetiva es de gran relevancia con sus múltiples vertientes, entre las que destacamos en este ejemplo particular: el principio de confianza y la 
prohibición de regreso. Eliminando así la conditio sine qua non. La imputación objetiva tiene como base principal la verificación de un nexo causal existente, con el fin de poder determinar los estándares legales a los cuales se pretenda imputar dicho resultado a un individuo. Surge por la ideología de la existencia de la necesidad de verificar más allá de la causalidad natural, considerando ésta insuficiente para atribuir un resultado a un individuo. Podría entenderse entonces que la imputación objetiva reclama que exista y se constate si existe relación entre la acción y el resultado.

\section{Definiciones de autores}

Es preciso indicar que los antecedentes esenciales de la teoría de la imputación objetiva, las localizamos en la teoría de la causalidad y el vínculo que une a la causa con un resultado es llamada precisamente relación de causalidad. La teoría de la imputación objetiva procura confirmar la causalidad jurídica, mediante una serie de criterios normativos, descritos en la siguiente fórmula: un resultado solo es objetivamente imputable cuando la acción causante del mismo ha creado un riesgo jurídicamente desaprobado (o típicamente relevante), que se ha realizado en un resultado típico y que pertenezca al ámbito o fin de protección de la norma infringida.

Para poder atribuir un resultado a una determinada conducta, se requiere establecer en primer término si entre esa ac- ción y ese resultado existe una relación de causalidad desde una perspectiva natural, Sin embargo, aún no se tiene resuelto el problema, es preciso, además determinar que ese vínculo natural interese al derecho penal. Pues bien, este último caso consiste en formular un juicio normativo, también conocido con el nombre de juicio de imputación objetiva, comprobar la existencia de la relación de causalidad es el primer paso de la imputación objetiva.

A continuación se expondrán los aspectos relevantes de la teoría de la imputación objetiva. La imputación objetiva está conformada por los siguientes elementos: A) La existencia de una relación de causalidad entre la acción y el resultado. B) El resultado debe ser la expresión de un riesgo desaprobado jurídicamente. C) El riesgo debe suponer una posibilidad objetiva de pretender la realización del resultado típico.

Se exige en un primer término comprobar si entre la acción y el resultado existe una causalidad. Si asisten simultáneamente estos presupuestos, la acción se adecúa al tipo penal, siendo de esta manera imputable para el agente. Se insiste en que el riesgo creado debe ser desaprobado en su totalidad jurídicamente, eliminando toda posibilidad de imputación a una acción que se encuentra cubierta por un riesgo permitido, en otras palabras, la acción que aunque sea peligrosa se encuentra en total permisibilidad debido a su beneficio o utilidad dentro del marco social. 
Como segundo término, se exige luego de haber sido comprobada la causalidad natural, verificar si en la acción se ha establecido un riesgo desaprobado, criterio que se reconoce como la imputación objetiva de la conducta. En relación con este segundo postulado tenemos el criterio de Zambrano Pasquel: "Un resultado causado por el actor solo debe ser imputado al tipo objetivo cuando la conducta del autor ha creado un peligro para el objeto de la acción no cubierto por el riesgo permitido, y ese peligro se ha realizado también en el resultado concreto."

Ponemos un ejemplo que en su gran mayoría los doctrinarios utilizan siempre: El automovilista que se encuentra conduciendo su vehículo por la ciudad, dentro del rango permitido de velocidad establecido en el reglamento correspondiente, causa lesiones a un peatón debido a que cruzó la calle sin tomar la debida precaución; las lesiones causadas no pueden ser imputadas al conductor del vehículo, por cuanto en ningún momento con su acción ejecutó un riesgo desaprobado jurídicamente y no lo aumentó por cuanto se encontraba dentro del límite de velocidad permitido, su comportamiento no llena las exigencias del comportamiento del tipo objetivo. Dicha acción no se adecúa al tipo penal de lesiones establecidas en el Código Orgánico Integral Penal. Sabemos que toda actividad humana genera riesgos, pero que son tolerados.
Por último, como tercer término se exige una posibilidad objetiva de pretender la realización del resultado típico, con esto se quiere manifestar que el riesgo debe suponer una posibilidad objetiva de pretender realizar el resultado típico. En este postulado, se debe observar si el resultado se puede concebir como realizado finalmente. Dicho en otras palabras, se observa la posibilidad de control del curso causal o del dominio humano para la realización de un resultado.

Otro ejemplo muy usado por los doctrinarios es aquel caso en donde un sobrino convence a su tío, al cual pretende heredar, que tome un viaje en avión, con la esperanza de que la aeronave sufra un percance y el tío fallezca. Jurídicamente se observan dos posturas respecto a este ejemplo en concreto: con la gran importancia que trae consigo la teoría de la imputación objetiva, no se le podría atribuir la muerte de su tío, ya que tomar un vuelo en una aeronave no constituye un riesgo desaprobado; por otro lado, a pesar de las malas intenciones que tenía el sobrino, no tenía el control de la falla mecánica de la aeronave que ocasionó la muerte al tío y por ende, no existió el evento en donde pueda realizar el tipo penal objetivo, que, en el caso concreto, sería el homicidio.

Aspectos generales en el COIP. En las normas que se encuentran en los artículos 22, 25, 28 y 29 del Código Orgánico Integral Penal, podemos apreciar que existe la positi- 
vización de la teoría de la imputación objetiva en el sistema jurídico penal ecuatoriano, que la convierten en un requisito fundamental de todo tipo penal. El art. 25 del COIP forja que el tipo penal requiera en su descripción los elementos exigidos por las conductas penalmente relevantes, que son aquellas conductas que ponen en peligro o producen resultados lesivos, que son realizados con la intervención de la voluntad (art. 22) a un bien jurídico protegido determinado. En el art. 28 del Código Orgánico Integral Penal tenemos a la omisión dolosa, que sin lugar a duda es cuando se deja de cumplir con el deber cuando se encuentra en la obligación jurídica de salvaguardar un bien. Por último, en el art. 29 del COIP tenemos a la antijuricidad, apreciada como un componente de la infracción penal, la cual radica en la apreciación que tiene el autor de la acción antijurídica cometida, y si se obtuvo o no el resultado querido, que es contradictorio a la ley penal.

Imputación objetiva de la conducta o el comportamiento. En lo que respecta a la imputación objetiva de la conducta, dentro del Código Orgánico Integral Penal, podría considerarse que se empieza a hacer referencia a la misma a partir del artículo 12 de la norma en mención El ejemplo clásico más utilizados dentro de la aplicación de la imputación objetiva es el siguiente: A, que se desenvuelve como taxista, transporta a B hacia un determi- nado sector; en la mitad de su traslado, un control policial para la marcha del vehículo y empieza con una revisión tanto del taxista como del pasajero; consecuentemente, encuentran al pasajero una mochila que poseía dos kilos de pasta base de cocaína. Por tratarse de un delito flagrante, se aprehende inmediatamente tanto al taxista como al pasajero.

Bajo este escenario se debe analizar que A cumple su rol social de taxista, el cual es llevar a un determinado lugar a un pasajero a cambio de una retribución económica. Lamentablemente, en Ecuador los centros de privación de libertad actualmente se encuentran sobrepoblados y tienen a muchos individuos que han pasado por situaciones iguales, y que aun no poseyendo la responsabilidad directa del lícito éstos pagan las consecuencias jurídicas, en muchos casos, por la falta de una buena defensa técnica.

Para poder comprender de forma correcta lo que es la imputación objetiva de la conducta, debemos tomar en cuarenta que ésta se encuentra dividida en varios factores o teorías, las cuales son:

- Riesgo prohibido o no permitido (la creación). Todos los individuos en la sociedad poseemos un determinado rol, el cual determina un tipo de riesgo, sin embargo, no siempre este riesgo será penalmente relevante, negando así en estos casos puntuales la imputación 
sobre dicho actuar, puesto que este accionar no ha dado paso a la creación de un riesgo importante de lesionar a un determinado bien jurídico protegido, es decir que no existe la creación de la peligrosidad o simplemente es insignificante, en caso contrario, que se logre verificar que sí existió la creación del riesgo no permitido capaz de lesionar al bien, sería atribuible de dicha imputación objetiva.

Cabe indicar que esta teoría se desprende de los ideales de Claus Roxin sobre el funcionalismo. Doctrinariamente algunos juristas la ubican en la imputación objetiva de la conducta, cuando este riesgo no ha generado lesiones, sin embargo, si las genera a criterio de conocedores del derecho, esta teoría (exceso de riesgo permitido) está bien ubicada en la imputación objetiva del resultado, la cual se profundizará $a$ posteriori. Para poder verificar si existió o no esta creación del riesgo en base a la conducta del autor, se deben tomar en cuenta las siguientes vertientes: la normativa extrapenal y las normas técnicas.

Un ejemplo de esta teoría: A, mientras conducía su vehículo, atropelló a B, ocasionándole la muerte; si A conducía en estado de embriaguez y B cruzaba por el paso peatonal, estamos frente a una creación de ese riesgo que acabó con el bien jurídico (la vida) de B, por lo tanto, es imputable. En este panorama aplicaremos las vertientes mencionadas, la norma extrapenal será la regulación de tránsito y su prohibición de conducir en estado etílico, por otra parte, el estándar técnico sería la prueba de alcoholemia.

Sin embargo, si A conducía a una velocidad prudente y en uso pleno de sus facultades, mientras que B cruzó en luz roja, se entendería que no existió la creación de un riesgo por parte de $\mathrm{A}$, y aunque $\mathrm{B}$ hubiese muerto, esto no podría ser atribuible de responsabilidad al conductor. El jurista ecuatoriano Edmundo Bodero expresa que: "El riesgo creado debe ser jurídicamente desaprobado, es decir no es posible imputar a la acción cubierta por un riesgo permitido, esto es, a la acción que, aunque peligrosa, está permitida por su utilidad social."

Disminución de riesgo. La disminución de riesgo es cuando el autor de dicho acto impide que suba a otro nivel aún más grave, por lo cual esa conducta no podría ser imputable al individuo que la ocasionó; un ejemplo de esto es: Aquel paramédico que, en el afán de reanimar a un individuo que está colapsando por ahogamiento, le practica un masaje cardiaco, producto del cual le lesiona una costilla. En este ejemplo, podemos analizar que el paramédico disminuyó el riesgo por salvaguardar aquel bien jurídico protegido, que es la vida del individuo, impidiendo así que se ejecutara la muerte, por lo tanto, no sería imputable el delito de lesiones. 
Un ejemplo adicional: A tumba de manera brusca a $B$ con el fin de impedir que un auto la atropelle; producto de dicho impulso B resulta lastimada. Si se analiza este ejemplo, no se le podría imputar el delito de lesiones a A, pues en caso de que éste no hubiese realizado dicho acto $B$ hubiese muerto, es decir que A disminuyó el riesgo de $B$.

Incremento de riesgo. Cabe en su totalidad la imputación de alguna conducta ilícita contra un individuo cuando éste incrementa el riesgo sobre un bien jurídico protegido ajeno; ejemplo de aquello es: Aquel conductor que excede la velocidad permitida. Si bien en el mundo fenomenológico conducir es un riesgo aprobado por la sociedad y normativa correspondiente, incrementar aquella velocidad significaría exceder el riesgo permitido, ya que pondría en peligro su vida y la de terceros.

Otro ejemplo: Una fábrica que se dedique a la elaboración y experimentación de químicos radiactivos es un riesgo aprobado jurídicamente, empero, si por algún motivo no se toma las medidas preventivas necesarias y se ocasiona algún evento que ponga en peligro a los trabadores y ciudadanos de sus alrededores, como el famoso accidente de Chernóbil, se habría excedido el riesgo permitido, por la tanto sería imputable.

- Principio de confianza. Esta teoría es implementada por Jakobs dentro del funcionalismo e implica una división funcional del rol, en donde se puede identificar los roles divididos de los individuos que intervienen en una conducta penalmente relevante. Este principio indica que todos los individuos actuamos conforme a determinado rol. "Principio de la confianza, conforme al cual todos y cada uno de los miembros de la sociedad confian en que los demás respetarán las reglas establecidas para evitar la puesta en peligro de un bien jurídico." (Garrido Mont, 2003).

El principio de confianza en el derecho penal está fuertemente ligado con el ámbito médico, específicamente en donde se interviene quirúrgicamente a una determinada persona, aunque su aplicación puede adaptarse a cualquiera caso en donde sea prudente. Tal como su nombre lo indica, este principio trata de aquella confianza que existe por parte de un individuo en relación a otro, cuyo actuar pensamos que será apegado a la norma, confiando así en que no se procederá a nada ilícito.

Sus primeros inicios surgieron en Alemania, cuando se atravesaba por una ola de múltiples casos de accidentes de tránsito; se empezó a considerar que existía la posibilidad, por parte del conductor, de haber confiado plenamente en la actuación correcta de otro individuo que conformaba dicho tránsito, eximiéndolo así de responsabilidad por los comporta- 
mientos erróneos de terceros. Las primeras sentencias emitidas en base al principio de confianza las realizó Reichsgericht, entre una de ellas destaca la siguiente:

Sentencia del 16 de septiembre de 1935: Se trata de un caso en el que el conductor, en un primer momento, había visto a unos niños jugando en medio de la calle y les había hecho señales para que le dejaran el camino libre. Los niños se desplazaron hacia la derecha y el conductor prosiguió su marcha. Al pasar junto a los niños, uno de ellos intentó volver a la carretera. Para evitar atropellarlo, el conductor giró rápidamente a la izquierda y chocó con una roca. Como resultado de la colisión murió su acompañante.

El tribunal de instancia, siguiendo la práctica habitual, había condenado al conductor por entender que, habiendo visto a los niños, debía contar con que de repente pudieran querer cruzar la calle, y que, en esa medida, debía disminuir la velocidad hasta el punto de estar en condiciones de poder dominar su vehículo.

El Reichsgericht, sin embargo, absuelve al conductor, explicando que, si bien se debe contar siempre con las conductas irracionales $y$ descuidadas de los terceros, sobre todo cuando son niños, ello no puede suponer una exigencia que vaya más allá de lo que cabe esperar conforme a la experiencia normal de la vida, y en este caso nada hacía pensar que los niños pudieran volver a intentar cruzar la calle.
No solamente fue en el ámbito de tránsito, sino también en escenarios completamente diferentes, en donde la aplicación de este principio era totalmente válida. Del principio de confianza se deriva lo que conocemos como la teoría general de roles, puesto que existen múltiples casos en donde el rol de un trabajador, dentro de una determinada empresa, debe poseer la confianza de quién es la autoridad máxima en conjunto con los subordinados que ejecuten un determinado deber. Del principio de confianza se expondría que: se basa en aquel ciudadano que se desenvuelve pensando que los demás ciudadanos actuarán de una forma estándar, apegados al cumplimiento de sus roles o funciones sociales.

Teoría general de los roles. Según Jakobs, la teoría general de los roles, aplicada dentro de la imputación objetiva, hace referencia al riesgo que posee cierto individuo cuando la responsabilidad de éste está condicionada por la decisión de un tercero; sin embargo, se excluyen aquellas decisiones condicionadas al propio individuo, es decir, a la subjetivas.

Todos los seres humanos dentro de la sociedad poseemos un rol específico, esto sirve al derecho penal para tener la garantía de que existirá una seguridad conforme al rol que desempeñe cada uno, por lo que, si dicho comportamiento no se ha despegado del rol correspondiente, será imposible imputarlo por algo que socialmente 
es adecuado, aunque dicha conducta haya producido alguna consecuencia a un bien jurídico protegido.

Con el surgimiento del funcionalismo, se trataba de enlazar el derecho penal y la política criminal desde los dos puntos funcionalistas que hemos mencionado en acápites anteriores. Jakobs implementa esta teoría de los roles por considerar que se trataría de la regulación del comportamiento o conducta de un individuo en el ámbito social, dando paso así al análisis de los resultados que dicho accionar traiga consigo.

Se hace referencia también a que el poder punitivo del Estado debe consistir en fortalecer al sistema social, con la finalidad de cumplir las expectativas que se tiene sobre determinada persona, con el fin de satisfacer a la norma, lo que está ligado con el funcionalismo normativo. Schúneman menciona diversos ejemplos, como este: la muerte mediante un colapso nervioso producto de un shock al recibir la noticia del accidente de un familiar; en este caso el resultado es previsible, pero se encuentra fuera del ámbito, no resultando conveniente desde el punto de vista político criminal la atribución del mismo al "mensajero".

- Prohibición de regreso. También es conocida como la teoría de la división funcional de los roles y fue implementada por Jakobs. Para este autor, no podría atribuirse responsabilidad penal a aquel que se comporta siempre apegado a su rol social; sin embargo, sí era imputable la extralimitación de ese rol, un ejemplo clásico de aquello es: A, en su rol de taxista, transporta a $B$ hasta un determinado domicilio; B baja del vehículo e ingresa, posteriormente roba dinero en dicha casa. En este ejemplo A no podría responder penalmente, pues él se limitó a lo que su rol de taxista enmarca, esto con la correspondiente justificación.

Posición de garante. La conducta penalmente relevante puede ser por acciones $\mathrm{u}$ omisiones; en el caso de las omisiones debemos analizar obligatoriamente si dicho individuo posee o no la posición de garante como tal, esto es, el rol obligatorio que posee para actuar en defensa del bien jurídico de otro. En ciertas ocasiones el individuo puede llegar a atribuirse posiciones de garante que naturalmente no le corresponde, una posición de garante:

- Por su naturaleza: la madre con su hijo (obligación de cuidado y protección de sus derechos desde su concepción). Si la madre, por ejemplo, permite que lo agredan sexualmente, así no hubiese participado, por su falta de protección estaría actuando bajo la modalidad de omisión. 
- Por su función: servidores públicos (han adquirido posición de garantes por sus cargos a desempeñar). Un ejemplo de esto es el policía en función de sus labores que observa un robo a su lado, sin embargo, no actúa en defensa del perjudicado, esto sería una omisión.

- Adquiridas sin ser propias: (aquella persona que voluntariamente adquiere dicha posición). Un ejemplo de aquello sería la persona que voluntariamente ayuda a un no vidente que intenta cruzar una calle transitada, sin embargo, a mitad de la calle decide abandonarlo y posterior a esto un vehículo lo impacta; aunque no exista una posición de garante obligatoria, el decidió voluntariamente apropiarla, por lo cual el no haber cumplido con lo que inició le atribuye una omisión.

- Imputación objetiva y víctima. En esta vertiente de la imputación objetiva se observa el principio de la autorresponsabilidad, o dicho de otra manera, de la responsabilidad propia, que no es otra cosa que: el autor puede quedar exento de responsabilidad penal cuando la propia víctima, con su comportamiento, no actúa de tal forma; entiéndase como que es la propia víctima quien ha sobrepasado un riesgo jurídicamente permitido por la ley penal.
Autopuesta en peligro de la víctima. Se analiza esta figura de la propia autopuesta en peligro de la víctima: quien con su propio comportamiento genera o en efecto aumenta el peligro de vulneración del bien jurídico protegido, del cual es titular.

La jurisprudencia excluye de la imputación objetiva aquellos supuestos en los que la creación del riesgo jurídicamente desaprobado no recae sobre el sujeto activo, si no que recae sobre el sujeto pasivo, es decir, en la víctima. Respecto a este postulado, nace la necesidad de decidir, por parte del juzgador, si la víctima ha perdido la protección del derecho penal, bajo el criterio de la autorresponsabilidad, o en efecto, se debe determinar la responsabilidad jurídica penal al autor que creó el riesgo.

Señala Jakobs que: "Sin embargo, mayor importancia práctica que estos casos de apoyos que exceden de lo obligado probablemente la tengan aquellos otros supuestos en los que la víctima con su propio comportamiento da la razón para que la consecuencia lesiva le sea imputada; casos en los que, por tanto, la modalidad de explicación no es la «desgracia», sino «la lesión de un deber de autoprotección» o incluso la "propia voluntad»" (Jakobs, 1998).

Para la comprensión de aquello, ponemos el ejemplo de una persona que observa que en una casa está siendo consumida por las llamas; al presenciar el retardo por parte de los bomberos decide ir al rescate de las personas que habitan en la casa y 
Ilustración 3. Imputación objetiva del resultado.

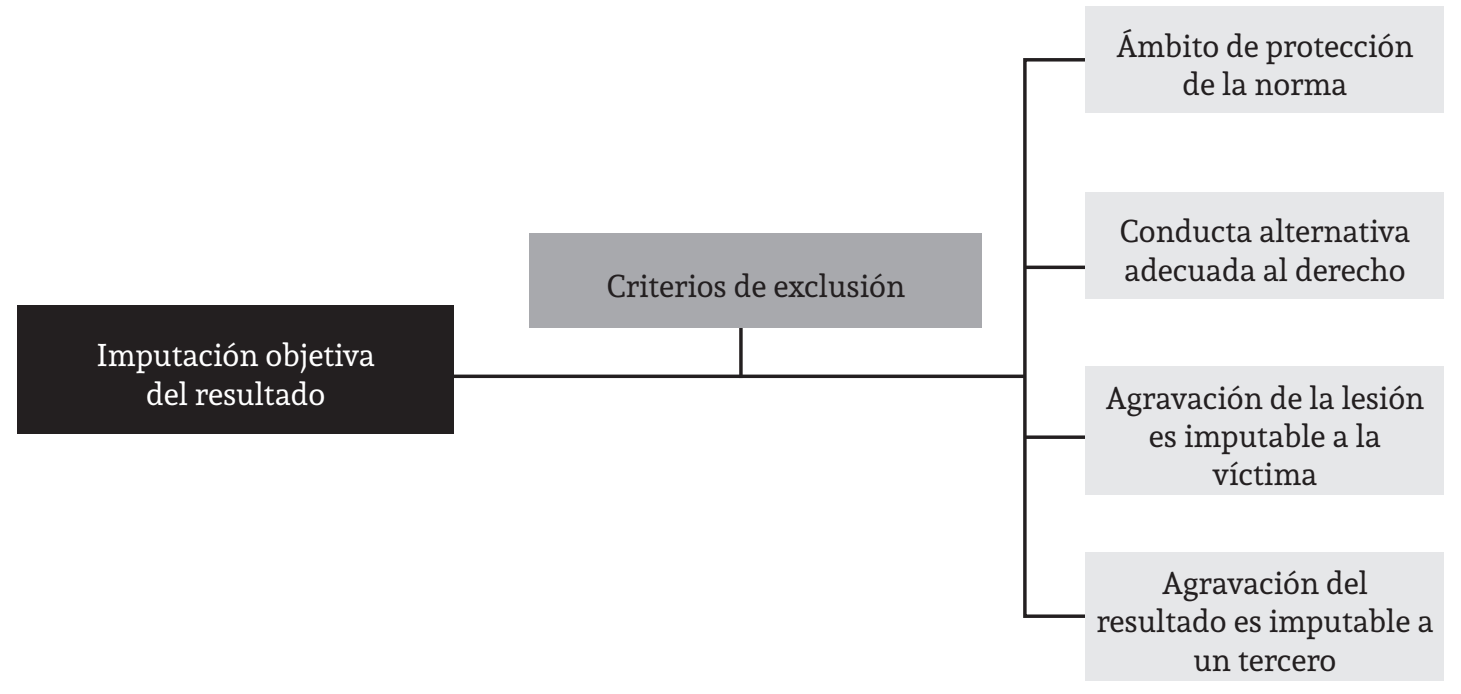

Elaborado por: Enderica, C. (2020) y Orellana, K. (2020).

producto de esta acción muere; voluntariamente provocó una autolesión al no tener preparación suficiente para incendios. Imputación objetiva del resultado. $\mathrm{Al}$ respecto señala el profesor Zambrano Pasquel lo siguiente: generalmente es imputable el resultado cuando constituye la realización de un peligro creado por el autor, de tal manera que se completa el tipo objetivo, pero aun así, puede excepcionalmente negarse la imputación cuando el radio de acción del tipo no incluye el impedir tales peligros y sus efectos.

Por ejemplo, Carlos circulaba en su vehículo en horas de la madrugada, encontrándose consciente de que los faros estaban en mal estado; con tales circunstancias en las que se encontraba el vehículo, tomó una curva a velocidad permitida por las autoridades de tránsito, pero debido a los faros en mal estado se desvió ha- cia el carril contrario, impactándose con el vehículo que venía en sentido opuesto, causándole la muerte al conductor.

Analizando este ejemplo, vemos que habría una conducta penalmente relevante a nivel de tipicidad, por cuanto al conducir un vehículo en mal estado se está creando un riesgo no permitido, que en el caso concreto es el deber objetivo de cuidado. Todo buen conductor, al haber estado el vehículo en buenas condiciones, hubiese podido evitar ese resultado y por ende, en este ejemplo de Carlos sí puede serle imputado objetivamente el resultado.

La imputación objetiva del resultado puede poseer las siguientes vertientes:

Según expone el jurista ecuatoriano Edmundo Bodero: "La teoría de la imputación objetiva plantea el problema de la atribución del resultado, constante en el tipo, no como una cuestión ontológica (natural, vinculado 
a la causalidad) sino como un problema normativo. Sirve, para descartar ab initio ${ }^{1}$ los riesgos penalmente irrelevantes..."

- Vínculo objetivo del comportamiento y el resultado. Dicho en acápites anteriores y sosteniendo la postura del maestro Günther Jakobs, ${ }^{2}$ es responsable aquella persona que se extralimita a su rol dentro de la sociedad y que, dentro de esta imputación objetiva del comportamiento, se encuentra de forma inherente lo que es la teoría de prohibición de regreso, teoría que verifica si existe o no una posición de garante. Evidentemente, se debe observar de forma estricta y precisa de qué manera se justifica el sujeto activo del delito o presunto autor, sí ha salido o no de su rol.

Recordemos que el del Código Orgánico Integral Penal tipifica acciones u omisiones que han sido realizadas en conciencia y voluntad, lo cual permite indicar que, si una persona realiza una acción sin voluntad o sin consentimiento, no se le puede imputar objetivamente un resultado y que es importante manifestarlo dentro de un

1 Traducido al español: "desde el principio".

2 "El hombre es un subsistema sico-psíquico, un centro de imputación o adscripción de responsabilidades. No importa la significación individual de las conductas, sino su significación social y la significación social no se deduce de la mente del autor, sino que ha de deducirse a partir del hecho en la mente del autor. Solo para el autor comienza el hecho con el dolo; para los demás, comienza al objetivarse”. Jakobs, G., Derecho penal. Parte general, Marcial Pons, pág. 203. proceso penal. Es por ello que se debe tomar en cuenta, de forma obligatoria, la posición de garante que tiene un individuo dentro de la sociedad, para poder alegar una omisión que es penalmente relevante dentro de lo que es la imputación objetiva del comportamiento o conducta; tenemos que revisar la posición de garante que tiene un individuo.

Por ejemplo, en el caso de aquellas personas que se encuentran en servicio activo policial, facultados plenamente para el cumplimiento del ejercicio de sus funciones, al momento de visualizar que se comete un hecho delictivo tienen la obligación de intervenir, por cual, debido a su naturaleza, todos los policías en servicio activo $\mathrm{y}$ facultados en sus funciones adquieren la posición de garante (Jakobs, G. 1997).

En el ejemplo citado, aquel policía que tiene dicha posición de garante, el cual, en el caso de no cumplir como tal y hacer caso omiso se está creando un riesgo penalmente relevante a través de dicha acción, pues el Código Orgánico Integral Penal es claro al respecto al indicar que aquellas personas que tienen la posición de garante, al percibir el cometimiento de un delito, tiene la obligación de denunciar o en su efecto poner a órdenes de autoridad competente. Para un mejor entendimiento, citamos el siguiente ejemplo del maestro Eugenio Zaffaroni: "Así, el comerciante que le vende a otro un cuchillo de cocina no quebranta su rol, aunque el comprador 
le exprese que lo usará para cometer un homicidio" (Zaffaroni et al., 2005).

Evitabilidad. La teoría de la evitabilidad, diseñada por Roxin, ${ }^{3}$ nos enseña que antes de imputar un resultado se tendría que examinar si es que un individuo ha estado en capacidad de evitar la consumación de un hecho, y no lo realiza.

Injerencia. Actualmente se encuentra en constante desarrollo y construcción por los doctrinarios. En todo caso, no es otra cosa que analizar cuándo un sujeto debe llegar a asumir la posición de garante, cuando esencialmente no la tiene, pero que en todo caso puede tenerla y asumirla por voluntad propia. Ejemplo: Miguel, quien es un hombre de la tercera edad, se encuentra cruzando la calzada; César quien es un transeúnte que pasa por el lugar, observa a Miguel cruzar la calle y decide ayudarlo (asume el rol de garante), e inesperadamente ocurre un accidente y

3 En una conferencia llevada a cabo en la Academia de Ciencias de Berlín, el 13 de mayo de 1970, Roxin manifestó un innovador modelo de derecho penal, enfocado sobre todo en la teoría del delito, mismo que dio a investigaciones con posterioridad. Él proponía, como meta principal, que se vincule tanto el derecho penal como la política criminal y que se restaure consecuentemente la categorización de los delitos desde el punto de vista de dichas políticas, entre las cuales se menciona: el otorgamiento de funciones en relación a la tipicidad, la aplicación de políticas sociales como herramienta de solución de aquellos conflictos que emanan causas justificantes, como método preventivo, la necesidad de una pena, añadidas a la culpabilidad y que posteriormente fundamenta la responsabilidad. Roxin además publicó sus conocimientos sobre la imputación objetiva, concibiendo la idea del injusto típico, como el acto realizado de aquel riesgo no permitido. Cfr. Muñoz Conde, F., prólogo a la Evolución de la política criminal, el derecho penal y el proceso penal, págs. 12-15. muere Miguel. César es objetivamente imputable por aquel resultado, debido a que ocupó un rol dentro de la sociedad que no lo tenía.

- Vínculos derivantes. Al respecto, el maestro Roxin manifiesta que la atribución de un resultado, cuando no es posible visualizarlo, se representa a través de los vínculos derivados; estos vínculos derivados son los siguientes:

Concurrencia de riesgo. Con respecto a este postulado, vemos que tiene un enfoque directamente en la dogmática penal y se debe analizar si esta concurrencia de riesgos es producida por una sola conducta o, en consecuencia, cuando existen varias conductas dentro de las cuales tenemos la conducta única y la conducta múltiple.

No es posible imputar objetivamente en el supuesto que, a pesar de que un individuo con su conducta creó un riesgo jurídicamente desaprobado, el resultado final es producto de otro riesgo ajeno a él. En este caso estamos hablando de una concurrencia de riesgos, por ejemplo: A dispara a matar a B, pero solo logra lesionarlo, pero luego $B$ muere producto de un incendio ocurrido en el hospital en el cual estaba siendo atendido, por lo tanto, la muerte de $B$ no puede ser atribuida a $A$.

Conducta única. En ocasiones, una sola conducta o comportamiento de un suje- 
to activo, puede poner en riesgo diversos bienes jurídicos protegidos de la norma, ejecutando tan solo una acción que es penalmente relevante. Claro ejemplo de la conducta única es el siguiente: José, en su intento de matar a Juan, quien se encuentra en el parqueadero o estacionamiento de un centro comercial, lanza una granada, provocándole lesiones en sus piernas y quemaduras alrededor de su cuerpo; también su acción ha averiado a dos vehículos que se encontraban estacionados cerca de José, lanzando una sola granada.

$\mathrm{Al}$ momento de establecerse una explosión, afecta de manera obligatoria a varios bienes jurídicos protegidos, ya que la producción de ese resultado conlleva a un delito contra la vida; también fue contra el derecho legítimo de la propiedad de aquellas personas que son titulares de los vehículos estacionados en el mismo lugar del centro comercial, de manera que, en una sola acción, se incurre en varios tipos penales.

Conducta múltiple. (Riesgo separable-inseparable y sobre condicionado). En cuanto al riesgo separable, claro ejemplo es el siguiente: Carlos, siendo servidor de una empresa de guardias de seguridad y laborando diariamente en el centro comercial "San Marino", fue atacado por unos hampones que pretendían entrar a robar al centro comercial; le provocaron heridas graves dos impactos de bala, quedando herido de muerte al evitar el ingreso de los atacantes.
Por ejemplo, Carlos fue auxiliado por miembros socorristas de ambulancias para trasladarlo de forma inmediata al hospital; en el trayecto donde es llevado al hospital, Roberto, quien se encuentra conduciendo su vehículo bajo el estado de embriaguez y a alta velocidad, impacta la ambulancia donde se movilizaba Carlos, produciéndole inmediatamente la muerte.

En el presente ejemplo tenemos de forma obligatoria dos comportamientos: el primer comportamiento es del hampón que intentaba ingresar a robar en el centro comercial y hiere de gravedad a la víctima por tratar de evitarlo; el segundo comportamiento es el de Carlos, quien conducía su vehículo en estado etílico. Nos encontramos frente a dos riesgos que son totalmente separados. De la conducta múltiple surgen las siguientes vertientes:

Riesgo inseparable. Al hablar de esta teoría, el riesgo resulta conformado por la unión de varias vertientes de responsabilidad. Se muestra cuándo no es posible separar la participación de cada interviniente en un acto y por ende no se puede demostrar cuál ha sido eficiente y cual no lo es. Tenemos el siguiente ejemplo: es el caso de dos empresas asociadas, dedicadas a la producción de productos tóxicos como el cloro y la pintura, ubicados cerca del Río Guayas, donde las personas, por lo general los moradores del sector, hacen uso de dicha agua al ser apta para el consumo humano. 
Dichas empresas, al sufrir un percance de derramamiento de esos productos por no tener el debido cuidado, desde su interior deciden abrir las compuertas conjuntamente y proceder al drenaje de las sustancias tóxicas, recayendo directamente al río y produciendo la muerte de una persona al ingerir el agua contaminada. En el ejemplo mencionado, por el tiempo en el que se realiza de una manera conjunta la apertura de las compuertas para drenar la sustancias tóxicas, el riesgo no es separable, ya que no se puede distinguir ni medir la proporción del grado de contaminación que aportó cada una de estas empresas, por lo tanto, cabe la imputación objetiva de resultado, ya que los intervinientes realizaron una contribución suficiente para producir aquel resultado.

Riesgo por indefensión. En este caso, es el autor con su comportamiento decide colocar a la víctima en una escenario o contexto de indefensión, frente a otros riesgos existentes que se encuentran a su alrededor. El autor no puede ser responsable por todos los daños inusuales que puedan suscitarse por aquella situación de indefensión de la víctima, sino que, en su efecto, sea responsable por aquellas que puedan esperarse de la situación en que se ha puesto a la víctima.

Por ejemplo: En una pelea callejera, por pandillas en disputa de territorio, Carlos golpea a Antonio, propiciándole una patada a la altura de la cabeza; producto de ese evento, Antonio cae al piso desmayado. Debido a aquello, Carlos procede a retirarse del lugar. Resulta que en aquella edificación en donde se encontraba Antonio desvanecido por el golpe, de manera repentina desciende un temblor, provocando el derrumbe y cayendo en su totalidad en el cuerpo de Antonio, produciéndole irremediablemente la muerte. Con dicho ejemplo surge la interrogante ¿cuál es el grado de responsabilidad de Carlos por haber golpeado a Antonio y haberlo dejado inconsciente, en base a que en aquella edificación se produjo un derrumbe por aquel temblor repentino, ocasionando la muerte a Antonio?

En respuesta a esta interrogante, según la teoría del maestro Claus Roxin, se debe excluir las circunstancias derivadas de la naturaleza, que puedan provocar un resultado. En este escenario, excluyendo esta causa natural originada por la propia naturaleza y que dicha edificación se haya encontrado en un estado de deterioro total, la producción de ese resultado sí sería imputable objetivamente a Carlos, puesto que conocía que por producto del golpe que proporcionó a Antonio lo dejó en estado de indefensión, ya que se encontraba inconsciente.

Riesgo derivado a terceros. Dentro de este grupo de riesgos se identifica por ser un proceso causal que ya ha iniciado, o que en efecto se encuentra en marcha para evitar la lesión de un bien jurídico protegido 
por la norma penal, y que dicho proceso ha sido interrumpido mediante un movimiento corporal de un tercero. Es el caso de que $A$, viendo a $B$, quien ha sido herido de bala, decide avisar a la ambulancia para que sea trasladado inmediatamente al hospital, pero no logra realizar la llamada porque un tercero le impide utilizar su teléfono al lanzarlo al agua.

Riesgo de curso salvador. Dentro de este grupo de riesgos es necesaria la inclusión de aquellos en los que por decisión del propio autor ha puesto en marcha un curso salvador, y que si no lo quebranta, va a conservar la integridad del bien jurídico protegido. Un claro ejemplo es el caso de aquella persona que lanza un salvavidas en una playa, mismo que se encuentra atado a una cuerda para mayor facilidad de salvamento de quien está en grave peligro de muerte por ahogamiento en el mar, pero decide retirar la cuerda con el salvavidas al darse cuenta de que la persona en problemas es su enemigo. En este caso el bien que se pretendía precautelar es la vida.

\section{Conclusiones}

1. La escuela que rige el sistema penal ecuatoriano es la funcionalista, desarrollada y estudiada por Roxin y Jakobs. La escuela funcionalista acoge los elementos proporcionados por la teoría del delito como lo son la tipicidad, la antijuricidad y la culpabilidad. Por medio de los instrumentos realizados para llevar a cabo la presente investigación, ha quedado en evidencia que existe un considerable desconocimiento de la teoría de la imputación objetiva y que no se vivió la transición de la escuela finalista a la funcionalista. Por medio de las encuestas se pudo cumplir con el objetivo de la investigación.

2. Nuestra conducta como personas ante la sociedad involucra un comportamiento administrado por un ordenamiento jurídico. El juicio de imputación requiere siempre de una conducta humana cotejada con una norma y que ésta a su vez vaya más allá de un riesgo jurídicamente desaprobado. La teoría de la imputación objetiva debe ser correctamente aplicada en una defensa técnica, analizando la conducta del supuesto infractor como antecedente y la consecuencia de dicha conducta como resultado de la misma, y si sobrepasa un riesgo jurídicamente permitido y para los administradores de justicia es correctamente aplicable esta teoría al garantizar el principio de legalidad.

3. Para poder adecuar una conducta a un tipo penal, es extremamente necesario demostrar la relación existente entre la conducta del sujeto y el resultado objetivo de aquella conducta, y que de esta manera exista la relación de causalidad de acción y resultado; observar objetivamente si ese resultado 
puede ser imputado a una persona que cumple un rol distinto en la sociedad y que generan acciones que arrojan un resultado, donde se observa principalmente si la persona se apartó o no de aquel rol del cual estaba obligado, y que no genere un riesgo jurídicamente desaprobado por la norma penal.

4. En el transcurso del presente trabajo de investigación, se ha podido determinar los criterios tomados en consideración del maestro Roxin, que determinan la teoría de la imputación objetiva de resultado, los cuales son: la disminución del riesgo, la creación de un riesgo jurídicamente relevante y el incremento del riesgo permitido.

5. Para el maestro Jakobs, la teoría de la imputación objetiva cumple una función esencial que permite determinar los ámbitos de responsabilidad de un sujeto dentro de la teoría del delito, así faculta constatar cuándo una conducta tiene carácter delictivo, dividiéndola en riesgo permitido, principio de confianza, prohibición de regreso y la actuación de la autopuesta en peligro de la propia víctima.

\section{Bibliografía}

Bodero, E. (4 de junio de 2013). La defensa penal científica. Ensayos Penales, 74.

Cancio Meliá, M. (2001). Líneas básicas de la teoría de la imputación objetiva. Argentina: Ediciones Jurídicas Cuyo.
Código Orgánico Integral Penal. (3 de febrero de 2014). Registro Oficial Suplemento 180. Quito, Ecuador: Asamblea Nacional. Obtenido de https://www.defensa.gob.ec/ wp-content/uploads/downloads/2018/03/ COIP_feb2018.pdf

Cornejo Aguiar, J. (9 de noviembre de 2015). Derecho Ecuador. Recuperado el 2 de febrero de 2020, de Derechoecuador.com: https:// www.derechoecuador.com/teoria-causalista-y-finalista-del-derecho-penal-\#_ftn1

Derecho Venezolano. (s.f.) Derechovenezolano.com. Recuperado el 21 de enero de 2020, de https://derechovenezolano.wordpress. com/2017/06/26/el-funcionalismo-moderado-de-roxin/

Garrido Montt, M. (2003). Derecho penal. Parte general, (Vol. II). Santiago de Chile: Editorial Jurídica de Chile.

Guillén, C. (2012). Debido proceso penal. Revista Jurídica, Universidad Católica de Santiago de Guayaquil, Guayaquil.

Jakobs, Günther. (1997). Derecho penal. Parte general. Marcial Pons.

Jakobs, Günther. (1998). La imputación objetiva en el derecho penal. Lima: Grijley.

Izalitur, A. (2014). Mediación del conflicto penal. Santiago: Editorian Nacional.

Ley Orgánica Reformatoria al Código Orgánico Integral Penal. (2019). Ley Orgánica Reformatoria al Código Orgánico Integral Penal.

Maraver, M. (s.f.) El principio de confianza en derecho penal, un estudio sobre la aplicación del principio de autorresponsabilidad en la teo- 
ría de la imputación objetiva. Madrid, España:

Universidad Autónoma de Madrid.

Orellana Faz, K. (19 de enero de 2020). Repositorio ULVR. Recuperado el 2 de febrero de 2020, de Error de tipo y error de prohibición vencible e invencible bajo la perspectiva del garantismo penal: http://repositorio.ulvr. edu.ec/handle/44000/3646

Schúneman, B. (1997). Consideraciones sobre la imputación objetiva. Congreso Internacional de Derecho Penal, (págs. 29-229).

Zaffaroni, E., Alagia, A. y Slokar Alejandro. (2005). Manual de derecho penal. Parte general. Buenos Aires: Ediar.

Zambrano Pasquel, A. (2000). La imputación objetiva. Quito. Obtenido de http:// www.alfonsozambrano.com/doctrina_penal/28102012/dpimputacion_objetiva.pdf

Zambrano Pasquel, A. (s.f.) Derecho Ecuador. Recuperado el 19 de enero de 2020, de https:// www.derechoecuador.com/Files/images/ Documentos/dpimputacion_objetiva.pdf 